\title{
BMJ Open Implications of private sector Hib vaccine coverage for the introduction of public sector Hib-containing pentavalent vaccine in India: evidence from retrospective time series data
}

\author{
Abhishek Sharma, ${ }^{1,2}$ Warren A Kaplan,, ${ }^{1,2}$ Maulik Chokshi, ${ }^{3}$ \\ Habib Hasan Farooqui, ${ }^{3}$ Sanjay P Zodpey $^{3}$
}

To cite: Sharma $A$,

Kaplan WA, Chokshi M, et al. Implications of private sector Hib vaccine coverage for the introduction of public sector Hib-containing pentavalent vaccine in India: evidence from retrospective time series data. BMJ Open 2015;5:e007038. doi:10.1136/bmjopen-2014007038

- Prepublication history and additional material is available. To view please visit the journal (http://dx.doi.org/ 10.1136/bmjopen-2014007038).

Received 28 October 2014 Revised 20 January 2015 Accepted 21 January 2015

CrossMark

For numbered affiliations see end of article.

Correspondence to Abhishek Sharma; abhi0991@bu.edu

\section{ABSTRACT}

Objective: Haemophilus influenzae type b (Hib) vaccine has been available in India's private sector market since 1997. It was not until 14 December 2011 that the Government of India initiated the phased public sector introduction of a Hib (and DPT, diphtheria, pertussis, tetanus)-containing pentavalent vaccine. Our objective was to investigate the state-specific coverage and behaviour of Hib vaccine in India when it was available only in the private sector market but not in the public sector. This baseline information can act as a guide to determine how much coverage the public sector rollout of pentavalent vaccine (scheduled April 2015) will need to bear in order to achieve complete coverage.

Setting: 16 of 29 states in India, 2009-2012.

Design: Retrospective descriptive secondary data analysis.

Data: (1) Annual sales of Hib vaccines, by volume, from private sector hospitals and retail pharmacies collected by IMS Health and (2) national household surveys.

Outcome measures: State-specific Hib vaccine coverage (\%) and its associations with state-specific socioeconomic status.

Results: The overall private sector Hib vaccine coverage among the 2009-2012 birth cohort was low (4\%) and varied widely among the studied Indian states (minimum $0.3 \%$; maximum $4.6 \%$ ). We found that private sector $\mathrm{Hib}$ vaccine coverage depends on urban areas with good access to the private sector, parent's purchasing capacity and private paediatricians' prescribing practices. Per capita gross domestic product is a key explanatory variable. The annual Hib vaccine uptake and the 20092012 coverage levels were several times higher in the capital/metropolitan cities than the rest of the state, suggesting inequity in access to Hib vaccine delivered by the private sector.

Conclusions: If India has to achieve high and equitable Hib vaccine coverage levels, nationwide public sector introduction of the pentavalent vaccine is needed. However, the role of private sector in universal Hib vaccine coverage is undefined as yet but it should not be neglected as a useful complement to public sector services.

\section{Strengths and limitations of this study}

- This study is the first nationwide analysis of the Haemophilus influenzae type b (Hib) vaccine uptake in India's private sector market. We found the private sector contribution to Hib vaccinations was low. It is likely that the private sector share is also low for other vaccinations but we do not know that.

- We provide baseline information about the state-by-state private sector coverage of $\mathrm{Hib}$ vaccine (prior to its public sector introduction). This case study explains how the non-traditional vaccines behave with respect to state-specific socioeconomic status in India when these vaccines are available only in the private sector market through out-of-pocket payments.

- We analysed private sector Hib vaccine uptake in 16 of a total 29 Indian states; these 16 states include all geographic regions of India and are home to around $90 \%$ of India's annual birth cohort of over 26 million.

- We assumed that all the children who initiated the Hib vaccine course in the private sector must have completed the same as scheduled, but that might not be true.

- We assumed that IMS Health data on vaccine sales from the hospital and retail pharmacies reflect the true total market utilisation.

\section{INTRODUCTION}

Vaccines against the bacterium Haemophilus influenzae type b (Hib), a major cause of vaccine-preventable morbidity and mortality among children worldwide, have been available in the Indian private sector market since 1997 but not in the public sector. ${ }^{1-4}$ Indeed, the actual state-by-state coverage of this private sector Hib vaccine has never been analysed. ${ }^{4-8}$ Nonetheless, the literature hints that the access to private sector Hib vaccine has been limited to urban and rich populations in India. ${ }^{4-11}$ 
India has the highest Hib disease burden in the world with around 2.4 million cases and 72000 Hib-related deaths annually, accounting for over $4 \%$ of total child deaths in India. ${ }^{2}{ }^{12}$ In June 2008, India's National Technical Advisory Group on Immunisations, the primary advisory committee advising the Government of India (GOI) regarding introduction of new vaccines and the Universal Immunization Programme (UIP), recommended nationwide public sector introduction of $\mathrm{Hib}$ vaccine into the UIP. ${ }^{12}$ However, it was not until 14 December 2011 that the GOI actually initiated the phased public sector introduction of a Hib-containing pentavalent vaccine in just two states, Kerala and Tamil Nadu. ${ }^{10} 13$ The Hib-containing pentavalent vaccine is intended to replace two other pre-existing UIP vaccines, viz, DPT (diphtheria, pertussis, tetanus) and Hep B (hepatitis B). This pentavalent vaccine is also expected to raise coverage of Hib and Hep B to the existing DPT coverage levels, which would otherwise be lower if $\mathrm{Hib}$ and Hep B vaccines were administered separately. ${ }^{5}$ Furthermore, the Hib vaccine is expected to demonstrate 'herd immunity' benefits in India, as seen in other developed and developing nations, ${ }^{14-18}$ meaning that immunising a proportion of the target population reduces disease incidence among unvaccinated children living in the same community.

In 2012, based on results from the pentavalent vaccine rollout in Kerala and Tamil Nadu, the GOI asserted that nationwide introduction of the pentavalent vaccine should proceed. ${ }^{19}$ Subsequently, the Hib-containing pentavalent vaccine was introduced in Haryana in December 2012, followed by five more states (Jammu \& Kashmir, Goa, Gujarat, Karnataka and Puducherry) in 2013. ${ }^{13}$ Thus, as of this writing, 8 of 29 Indian states have begun public sector delivery of Hib-containing pentavalent vaccine. We do not know the extent of the eight-state public sector coverage of Hib-containing pentavalent vaccine.

Nonetheless, in the majority of Indian states, the Hib vaccine is presently available only in the private sector market and is not available in the public sector. In this report, we use information from monitoring state-by-state private sector uptake of Hib vaccine in 16 of the 29 Indian states in order to understand the possible challenges facing India's upcoming public sector rollout of Hib-containing pentavalent vaccine (scheduled April 2015). ${ }^{13}$ Specifically, we estimate the Hib vaccine coverage rates in the studied states for the period when the vaccine was available only in the private sector market as a guide to determining how much coverage the public sector will need to bear in order to achieve complete coverage.

\section{METHODS}

For the purpose of this study, we define the 'private sector Hib vaccine coverage' as the percentage of eligible birth cohort in a given state that received three doses of Hib vaccine in the private sector market. The private sector
Hib vaccine coverage was calculated among the 2009-2012 birth cohorts for all studied states, except in the cases of Kerala and Tamil Nadu. For Kerala and Tamil Nadu, it was calculated for years 2009-2011 because these states introduced Hib-containing pentavalent vaccine in the respective public sectors starting mid-December 2011. We further define Hib vaccine 'uptake' as the number of Hib vaccine doses sold in a given state/region's private sector market over specified years.

\section{Data sources}

For information regarding the volume of Hib vaccines sold, we obtained data on 2009-2012 yearly sales of vaccines, by number of doses, in the private sector market of 16 of 29 Indian states, from IMS Health (originally called Intercontinental Marketing Services). ${ }^{20}$ IMS Health is a for-profit company that collects information on services and technology for the healthcare industry. The IMS Health data are typically collected from various stages in the retail pharmaceutical supply chain (ie, from pharmaceutical manufacturers and importers, wholesalers, distributors and subdistributors of medicines) on the basis of annual audits in India. Volume data typically captured by IMS Health are aggregated and include medicine pack details and quantity. IMS data have been used for several studies. ${ }^{21-23}$ The present data are state specific (although data from Punjab and Haryana are combined) and are generated from annual sales audits across private hospitals and retail pharmacies in India. We separated the data by state for sales of the Hib vaccines. Although the choice of 16 states was driven by data availability, these are the major Indian states (by area and population) representing around $90 \%$ of India's annual birth cohort of 26 million. ${ }^{24}{ }^{25}$ These states include all geographic regions of the country: North (Punjab+Haryana, Delhi, Rajasthan), Central (Uttar Pradesh, Madhya Pradesh), East (West Bengal, Orissa, Bihar), West (Gujarat, Maharashtra), South (Andhra Pradesh, Karnataka, Kerala, Tamil Nadu) and Northeast (Assam).

To establish the denominator for the population (birth cohort) at need, we referenced the 2011 census of India ${ }^{24}$ (conducted every 10 years) for state-specific statistics regarding the population size and birth rates (overall and urban). We also obtained state-specific data on socioeconomic indicators from the latest representative household surveys, viz DHS/NFHS 2005-2006 and Unicef CES 2009. ${ }^{25-29}$

\section{Calculating estimates for private sector Hib vaccine coverage}

We made certain assumptions based on best-case scenarios, that is, the actual private sector Hib vaccine coverage can be lower than that reported, but not higher. These assumptions are (1) every Hib vaccination course initiated in the private sector was completed with a total of three doses at 6, 10 and 14 weeks $^{30} 31$ and (2) the 
vaccine wastage was nil. Since vaccine wastage is inevitable, we expect the actual Hib vaccine coverage to be lower than that reported so our estimates reflect an upper limit. However, it is reasonable to assert that the private sector vaccine wastage was low because: (1) nearly all the sold Hib vaccine products were single use/ dose units and (2) these private sector vaccines are primarily paid out-of-pocket (OOP) by the parents. ${ }^{4} 32$ These vaccine products would therefore be considered a valuable resource by health providers as well as their clients (parents).

Private sector Hib vaccine coverage was calculated in three steps.

\section{Children fully vaccinated in the private market}

We calculated the number of children vaccinated with Hib vaccine in a given state by dividing the total vaccine doses sold in the state's private sector market from 2009 to 2012 (year 2012 excluded for Tamil Nadu and Kerala as explained earlier) with the number of scheduled doses, that is, three. ${ }^{30}$ All brands of both monovalent (Hib only) and combination (DPT $+\mathrm{Hib}+$ Polio, DPT $+\mathrm{Hib}$, etc) vaccines were included in the $\mathrm{Hib}$ vaccine sales data set.

$$
\begin{aligned}
& \text { Children fully vaccinated in private sector } \\
& =\left(\frac{\text { Total Hib vaccine doses sold in private sector }}{\text { Doses scheduled to complete course }(=3)}\right)
\end{aligned}
$$

\section{Birth cohort eligible for Hib vaccination}

We applied the state-specific births rates (live birth per 1000 population) to the total population of the respective states in order to estimate the state-specific annual birth cohorts. ${ }^{24}{ }^{25}$ Also, we calculated the urban birth cohorts of these states by applying the urban birth rate to the urban population of the respective states. Since birth rates (both urban and rural) in Indian states have been nearly constant from 2006 to 2012, we tripled the annual birth cohorts of Kerala and Tamil Nadu and quadrupled those of the remaining states to obtain statespecific eligible birth cohorts for the respective calculation years. ${ }^{25}$

\section{Private sector Hib vaccine coverage}

We calculated Hib vaccine coverage among the 20092012 birth cohort for overall and for state-wise (20092011 for Kerala and Tamil Nadu). The 'overall coverage' means the percentage of total eligible children from the 16 studied states who received the Hib vaccine in the private sector market. For coverage calculations, we considered two scenarios: 'statewide' and 'urban'. The 'statewide' coverage considers that the sold Hib doses are consumed by any child in the entire birth cohort (both rural and urban) of the respective state. In contrast, the 'urban' coverage model assumes that the sold Hib doses were consumed only by the urban birth cohort. ${ }^{11}$

'Statewide' Hib vaccine coverage (\%)

$=\left(\frac{\text { From step 1: Children fully vaccinated in private sector }}{\text { From step 2: Birth cohort (rural + urban) of the respective state }}\right)$

$\times 100 \%$

'Urban' Hib vaccine coverage (\%)

$=\left(\frac{\text { From step } 1: \text { Children fully vaccinated in private sector }}{\text { Step } 2: \text { Urban birth cohort of the respective state }}\right)$

$\times 100 \%$

\section{Sensitivity analyses}

We expect the possible vaccine wastage to be $1-2 \%$. Further, there could be some variation in the estimations of IMS Health vaccine sales. We conducted a sensitivity analysis to estimate the possible impact of vaccine wastage and of any possible variation in IMS Health estimation of actual sales on the overall private sector Hib vaccine coverage.

\section{Statistical analyses}

Using statistical software 'R' V.3.0.3, ${ }^{33}$ we performed bivariate Spearman's rank correlation analysis to study the association between the calculated private sector Hib vaccine coverage (state-wide) and those state-specific socioeconomic factors that influence vaccination coverage rates. These socioeconomic factors include per capita gross domestic product (GDP), level of urbanisation, female literacy rate, proportion of marginalised populations, availability of paediatricians and birth deliveries in private sector facilities. ${ }^{26} 27{ }^{34-36}$ The sample size is small ( $\mathrm{n}=15$ : total 16 states but two states ie, Punjab and Haryana are considered as one observational unit in the IMS Health data set) and the non-parametric Spearman's correlation test is more conservative than the Pearson's correlation as the former does not assume a normal distribution of variables, linear relationship between the two variables, or absence of significant outliers. ${ }^{37}$

We note that per capita GDP is a significant driver of health spending in India. It influences the socioeconomic factors listed above. ${ }^{38}{ }^{39}$ As the private sector Hib vaccines under analysis were primarily paid through OOP payments, ${ }^{42}$ we might expect the per capita GDP to modify associations between the private sector $\mathrm{Hib}$ vaccine coverage and the other socioeconomic factors. Therefore, in addition to bivariate correlations, we also calculated Spearman's partial correlations, using the statistical package R 'ppcor', ${ }^{40}$ to test if per capita GDP is an explanatory variable for associations between the state-specific private sector Hib vaccine coverage and the other socio-economic factors (see online supplementary appendix). For all the correlational analyses, we used an $\alpha$ significance level of 0.05 to test the null hypothesis that Spearman's correlation coefficient, $r$, is equal to 0 . 
We also tested if the private sector Hib vaccine annual uptake and the 2009-2012 Hib vaccine coverage varied between the capital/metropolitan cities and rest of the state in three Indian states (Maharashtra, Tamil Nadu and West Bengal). For this analysis, we calculated the birth cohorts for the capital/metropolitan cities and for the rest of the respective states. The choice of these three states was driven by the availability of within-state vaccine sales data.

\section{RESULTS}

\section{Private sector Hib vaccine coverage among 2009-2012} birth cohort

More than $50 \%$ of birth cohort live in the states of Bihar, Rajasthan, Uttar Pradesh, Assam and Madhya Pradesh. On the whole, around $25 \%$ of the birth cohort in the studied states live in urban areas, ranging from a low of $8.8 \%$ in Bihar to a high of $95.8 \%$ in Delhi (table 1).

The overall statewide Hib vaccine coverage was found to be $4 \%$, ranging from a minimum of $0.3 \%$ in Assam to a maximum of $4.6 \%$ in Punjab+Haryana. Considering the 'urban' model, where we assume that all the sold Hib vaccine doses were consumed by the urban birth cohort, we found that the overall urban coverage was $15.7 \%$ (minimum $1.3 \%$; maximum $11.7 \%$ ). Table 1 and figure 1 present detailed state-specific private sector Hib vaccine coverage among the 2009-2012 birth cohort.

\section{Hib vaccine coverage in metropolitan areas 2009-2012}

For selected states (Maharashtra, Tamil Nadu and West Bengal), we calculated the annual Hib private sector vaccine uptake and coverage levels (2009-2012) in the capital/metropolitan city of the state as compared to the rest of the state (ie, state excluding the capital/ metropolitan city). We found that the annual statespecific Hib vaccine uptake (2009-2012) was highly concentrated in the capital/metropolitan cities. For instance, in 2012, the Hib vaccine uptake in the capital/ metropolitan areas of Mumbai, Chennai and Kolkata represented $45.1 \%, 46.2 \%$ and $70.9 \%$ of total uptake in the states of Maharashtra, Tamil Nadu and West Bengal, respectively (table 2 , column 3 ).

The private sector Hib vaccine coverage was 2.9, 4.0 and 15.2 times higher among the birth cohort of the capital/metropolitan cities (Mumbai, Chennai and Kolkata, respectively) as compared to that in the rest of the state, suggesting inequity in Hib vaccine access as delivered by the private sector (table 2 , column 4 ).

\section{Association between private sector Hib vaccine coverage and socioeconomic factors}

Table 3 presents the results of bivariate Spearman's correlational analysis between private sector Hib vaccine coverage and state-specific socioeconomic factors. We found that the private sector Hib vaccine coverage is mainly limited to the states with high per capita GDP $(r=0.65 ; \mathrm{p}$ value $=0.01)$ and urbanisation $(\mathrm{r}=0.57$; $\mathrm{p}$ value $=0.03$ ) (tables 2 and 3$)$. Per capita GDP and urbanisation are both strongly correlated with each other ( $r>0.9$; $p$ value $<0.001$; data not presented), and are further associated $(r \geq 0.9$; $\mathrm{p}$ value $<0.001$; data not presented) with births in the private sector and number of paediatricians per 1000 children. We also found a strong association between private sector Hib vaccine coverage and births in private sector heath facilities $(\mathrm{r}=0.72$, $\mathrm{p}$ value $=0.004)$, and number of paediatricians per 1000 children $(\mathrm{r}=0.66$, $\mathrm{p}$ value $=0.01)$. Private sector Hib vaccine coverage was insignificantly correlated $(r=0.38$, $p$ value $=0.16)$ with female literacy rate, and was significantly $(\mathrm{r}=0.60, \mathrm{p}$ value $=0.02$ ) correlated with state's full vaccination coverage rates (ie, proportion of children who received one dose of BCG and measles and three doses of DPT and polio vaccines).

Holding per capita GDP constant (see online supplementary appendix), the Spearman's partial correlational analysis found that the bivariate correlation coefficients between private sector Hib vaccine coverage and urbanisation, proportion of schedule caste population and proportion of children receiving primary vaccinations in private sector health facilities, dropped close to zero. Considerable reductions in coefficients were also observed in associations between private sector Hib vaccine coverage and other socioeconomic factors when per capita GDP was held constant.

\section{Sensitivity analysis}

We expect the possible vaccine wastage to be $1-2 \%$, and there could be some variation in the estimations of IMS Health vaccine sales. Therefore, we recalculated the $\mathrm{Hib}$ vaccine coverage and found that with every $1 \%$ vaccine dose wasted/overestimated, the overall urban and statewide Hib vaccine coverage reduced by 0.16 and 0.04 percentage points, respectively.

\section{DISCUSSION}

To the best of our knowledge, this is the first nationwide analysis of private sector Hib vaccine uptake and coverage in India. We estimate that Hib vaccine coverage among the 2009-2012 birth cohort (when the vaccine was available only in the private market) in India was low (4\%) and varied widely among the Indian states (minimum 0.3\%; maximum $4.6 \%$ ) (see table 1 and figure 1).

Private sector Hib vaccine coverage is strongly and significantly associated with a given state's wealth (eg, per capita GDP, level of urbanisation) and, as expected, private sector birth deliveries and number of paediatricians per 1000 children. With respect to the association with number of paediatricians, studies have found that private paediatricians in India assess the paying capacity of their client (parents) and prescribe/recommend expensive vaccines such as $\mathrm{Hib}$ vaccine accordingly (selective prescribing). ${ }^{4} 11$

Not surprisingly, private sector Hib vaccine coverage was negatively associated with the proportion of the population living below the poverty line. It was, however, insignificantly correlated with female literacy rate. This 


\begin{tabular}{|c|c|c|c|c|c|c|c|c|c|c|c|}
\hline \multirow[b]{2}{*}{ State } & \multirow[b]{2}{*}{ Population* } & \multirow{2}{*}{$\begin{array}{l}\text { Urban } \\
\text { population } \\
\text { as \% of total } \\
\text { population* }\end{array}$} & \multicolumn{2}{|c|}{$\begin{array}{l}\text { Birth rate (live } \\
\text { births per } 1000 \\
\text { population) } \dagger\end{array}$} & \multicolumn{2}{|c|}{$\begin{array}{l}\text { Estimated annual } \\
\text { birth cohort }\end{array}$} & \multicolumn{2}{|c|}{$\begin{array}{l}\text { Total birth cohort } \\
\text { (for respective years)‡ }\end{array}$} & \multirow{2}{*}{$\begin{array}{l}\text { Vaccinated cohort } \\
\text { based on number } \\
\text { of Hib doses sold§ }\end{array}$} & \multirow[b]{2}{*}{$\begin{array}{l}\text { 'Statewide' } \\
\text { coverage (\%) }\end{array}$} & \multirow[b]{2}{*}{$\begin{array}{l}\text { 'Urban' } \\
\text { coverage (\%) }\end{array}$} \\
\hline & & & Overall & Urban & Overall & Urban & Overall & $\begin{array}{l}\text { Urban } \\
\text { (\% of overall cohort) }\end{array}$ & & & \\
\hline \multicolumn{12}{|l|}{ North } \\
\hline Punjab+Haryana & 53094800 & 36.2 & 19.0 & 17.4 & 1008801 & 333288 & 4035204 & 1333153 (33.0) & 155516 & 3.9 & 11.7 \\
\hline Delhi & 16753235 & 97.5 & 17.5 & 17.2 & 293181 & 280951 & 1172726 & 1123807 (95.8) & 17509 & 1.5 & 1.6 \\
\hline Rajasthan & 68621012 & 24.9 & 26.2 & 22.5 & 1797871 & 383986 & 7191482 & 1535944 (21.4) & 48819 & 0.7 & 3.2 \\
\hline \multicolumn{12}{|l|}{ Central } \\
\hline Uttar Pradesh & 199581477 & 22.3 & 27.8 & 23.7 & 5548365 & 1053389 & 22193460 & $4213556(19.0)$ & 106330 & 0.5 & 2.5 \\
\hline Madhya Pradesh & 72597565 & 27.6 & 26.9 & 20.1 & 1952874 & 403180 & 7811498 & $1612720(20.7)$ & 42802 & 0.5 & 2.7 \\
\hline \multicolumn{12}{|l|}{ East } \\
\hline West Bengal & 91347736 & 31.9 & 16.3 & 11.5 & 1488968 & 334794 & 5955872 & 1339176 (22.5) & 46157 & 0.8 & 3.4 \\
\hline Orissa & 41974218 & 16.6 & 20.1 & 14.7 & 843681 & 102425 & 3374727 & 409702 (12.1) & 19391 & 0.6 & 4.7 \\
\hline Bihar & 103804637 & 11.3 & 27.7 & 21.7 & 2875388 & 254314 & 11501553 & $1017256(8.8)$ & 79023 & 0.7 & 7.8 \\
\hline \multicolumn{12}{|l|}{ West } \\
\hline Gujarat & 60383628 & 42.6 & 21.3 & 19 & 1286171 & 488745 & 5144685 & $1954980(38.0)$ & 70338 & 1.4 & 3.6 \\
\hline Maharashtra & 112372972 & 45.2 & 16.7 & 15.8 & 1876629 & 802877 & 7506514 & 3211511 (42.8) & 103596 & 1.4 & 3.2 \\
\hline \multicolumn{12}{|l|}{ South } \\
\hline Andhra Pradesh & 84665533 & 33.4 & 17.5 & 16.6 & 1481647 & 468857 & 5926587 & 1875429 (31.6) & 100636 & 1.7 & 5.4 \\
\hline Karnataka & 61130704 & 38.7 & 18.8 & 17.2 & 1149257 & 406595 & 4597028 & 1626380 (35.4) & 74940 & 1.6 & 4.6 \\
\hline Keralaף & 33387677 & 47.7 & 15.2 & 14.4 & 507492 & 229333 & 1522478 & 687999 (45.2) & 70039 & 4.6 & 10.2 \\
\hline Tamil Naduๆ & 72138958 & 48.4 & 15.9 & 15.7 & 1147009 & 548169 & 3441028 & $1644508(47.8)$ & 21065 & 0.6 & 1.3 \\
\hline \multicolumn{12}{|l|}{ Northeast } \\
\hline Assam & 31169272 & 14.1 & 22.8 & 15.5 & 710659 & 68120 & 2842637 & 272481 (9.6) & 8237 & 0.3 & 3.0 \\
\hline Overall (16 states) $\ddagger$ & & & & & & & 23967997 & $6159027(25.7)$ & 964401 & 4.0 & 15.7 \\
\hline $\begin{array}{l}\text { *2011 Census of Ino } \\
\text { †GOI Planning Com } \\
\text { †Calculation years: } \\
\text { §IMS Health. } \\
\text { ๆCalculations for yea } \\
\text { GOI, Government of }\end{array}$ & $\begin{array}{l}24 \\
\text { ssion } 2014 .^{25} \\
9-2011 \text { for T }^{1} \\
\text { 2009-2011. } \\
\text { dia; IMS, Inte }\end{array}$ & iil Nadu and $\mathrm{r}$ & ala an & s. & for the & the 14 & & & & & \\
\hline
\end{tabular}




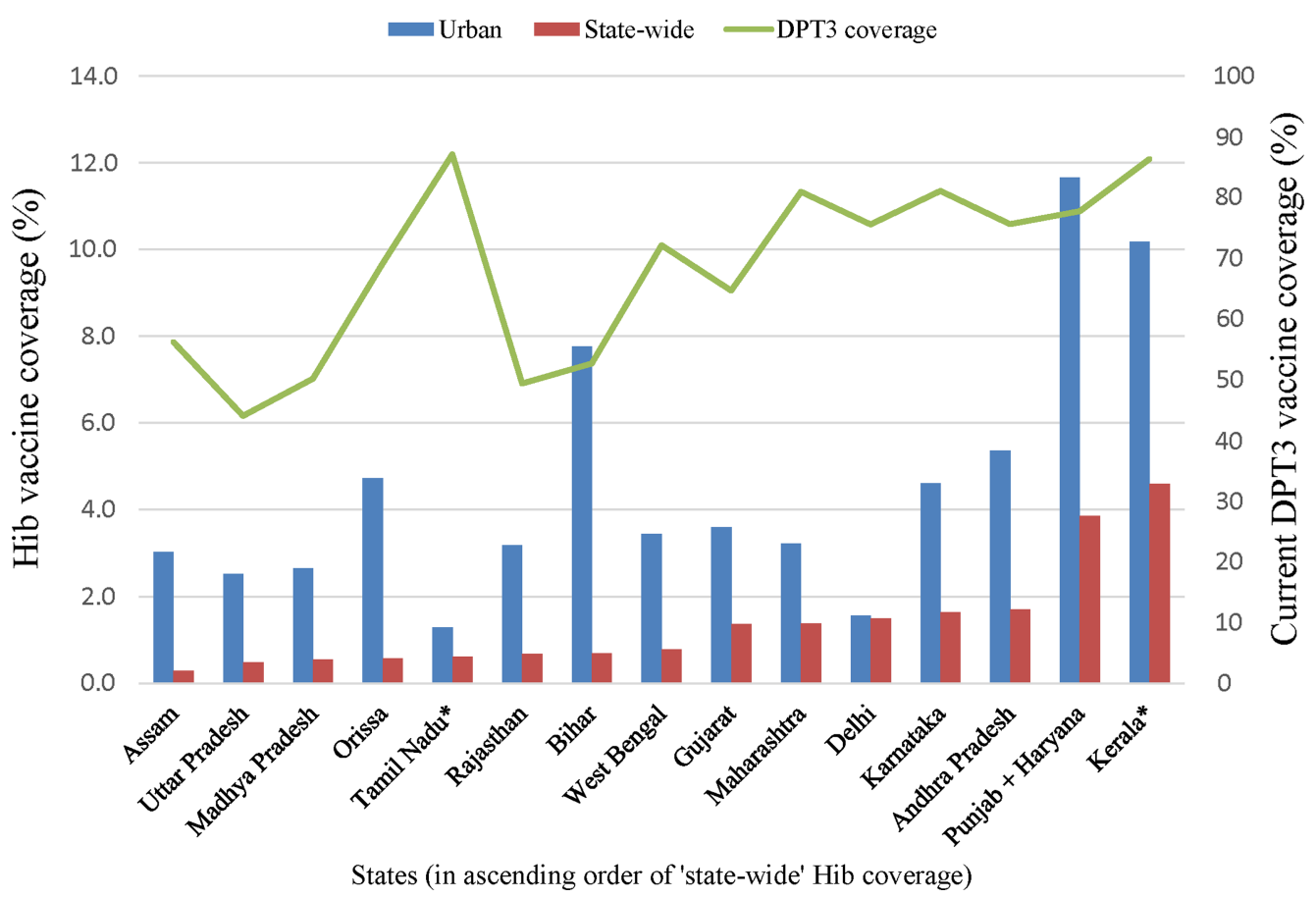

Figure 1 State-specific Hib vaccine coverage among the 2009-2012 birth cohort. *Hib vaccine coverage calculated among the 2009-2011 birth cohort in these states (DPT, diphtheria, pertussis, tetanus; Hib, Haemophilus influenzae type b).

association of private sector Hib vaccine coverage and female literacy is inconsistent with studies that report a significant, strong positive correlation between female literacy (maternal literacy and health seeking behaviour) and coverage rates of the traditional public sector vaccines. ${ }^{36}$ We infer that the weak association of private sector Hib vaccinations with female literacy could be multifactorial, for example, most mothers are seeking vaccination services in public sector facilities, private paediatricians show selective prescribing behaviour and parent's may have insufficient purchasing capacity to access the expensive Hib vaccines from the private sector market. ${ }^{411} 3241$

On the whole, we infer that private sector Hib vaccine coverage depends on urban areas with good access to the private sector, parent's purchasing capacity and private paediatricians' prescribing practices. However, our Spearman's partial correlational analysis suggests that these factors may operate on private sector Hib vaccine coverage primarily through per capita GDP, as expected (see online supplementary appendix).

Despite the availability of Hib vaccine in India's private market since 1997, the nationwide private sector Hib vaccine coverage remains extremely low (about 4\%), along with prevailing socioeconomic inequity among and within population groups. If India has to achieve high and equitable Hib vaccine coverage levels, the ongoing public sector introduction of the Hib-containing pentavalent vaccine appears to be required, but it will be challenging for several reasons.

First, the post-introduction evaluation (PIE) of Hib-containing pentavalent vaccine in Kerala and Tamil $\mathrm{Nadu}$ reported its successful incorporation and acceptance among the community and healthcare staff (ie, vaccine wastage was reduced by $50 \%$ and the coverage rates remained constant; data not presented in the available PIE document). ${ }^{19}$ However, Kerala and Tamil $\mathrm{Nadu}$ - the states with the best performing public sectors-are not truly representative of many other Indian states that have suboptimal public sector vaccination machinery. The positive results of the PIE from Kerala and Tamil Nadu do not necessarily mean that all the Indian states are prepared to introduce and benefit from the important Hib vaccine.

Second, analysis of private sector vaccine rollout in the absence of the public sector teaches us that the public sector rollout of the Hib-containing pentavalent vaccine will be difficult in those Indian states that are primarily rural with poor access to private and public sectors. Since one of the major barriers to private sector Hib vaccine coverage, that is, the need to pay OOP, will be eliminated with the public sector introduction of pentavalent vaccine, more mothers (parents) with low purchasing capacity would likely opt for the vaccine. However, this alone does not necessarily ensure high coverage of Hib-containing pentavalent vaccine, as the coverage of other free-of-cost public sector traditional vaccines remains low in India. ${ }^{27}$ India still has a long way to go to achieve high Hib vaccination levels through the ongoing public sector introduction of the pentavalent vaccine.

Finally, and as aforementioned, the pentavalent Hib vaccine contains DPT, and will replace the current DPT vaccine. Although we have found private sector Hib vaccine coverage rates to be low, the public sector introduction of Hib-containing pentavalent vaccine is presumed to increase state-specific Hib vaccine coverage 


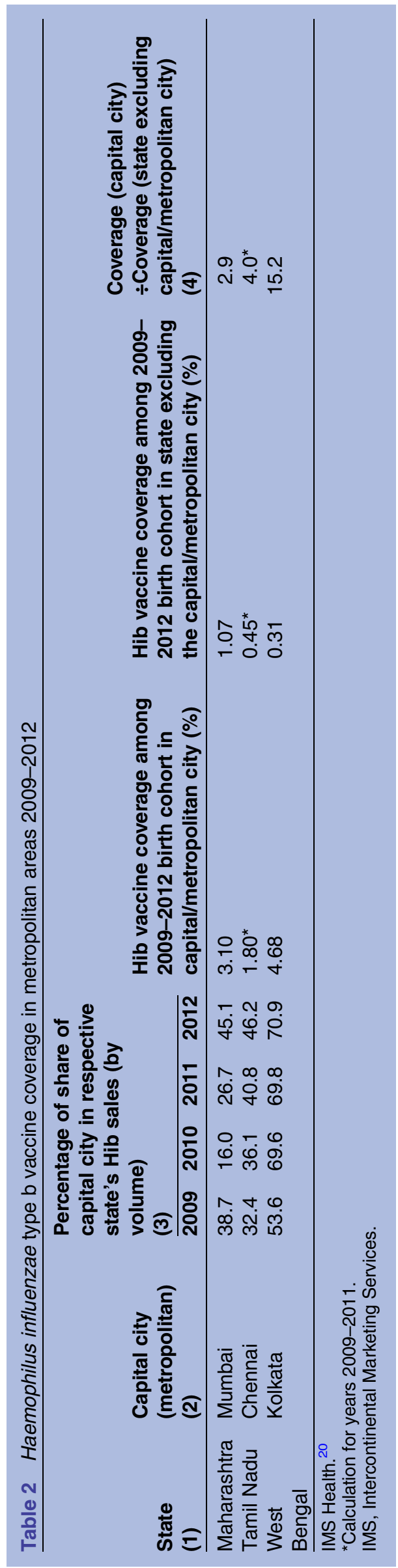

rates from their presently low private sector Hib vaccine coverage rates to the state-specific DPT coverage levels (see figure 1). Unfortunately, the existing public +private DPT coverage levels are low $(<60 \%)$ in poor Indian states such as Bihar, Rajasthan, Uttar Pradesh, Assam and Madhya Pradesh, where more than $50 \%$ of Indian children live. ${ }^{26} 273442$ This suggests that coverage levels of the new Hib (and DPT)-containing pentavalent vaccine may be similar to the present weak coverage of DPT alone in these states.

In figure 1, the green line shows the current statespecific DPT-alone vaccine coverage levels to which the Hib vaccine coverage levels are expected to rise with the introduction of Hib (and DPT)-containing pentavalent vaccine (the provided DPT3 vaccine coverage levels are the average of values reported by DHS/NFHS 2005$2006^{26}$ and Unicef CES $2009^{27}$ ).

While 'herd immunity' benefits are anticipated from even partial Hib vaccine coverage, there is lack of evidence regarding the coverage levels required to restrict Hib transmission in India. ${ }^{18}$ Children living in poor states are more prone to invasive Hib diseases than those in the wealthier states. ${ }^{12}$ Similarly, children in ruralurban migrant populations and families living in informal settings/slum areas are often marginalised from public sector vaccination benefits. ${ }^{43}$ If we assume a low coverage threshold of $60 \%$ for herd immunity in India, a densely populated country, many Indian states would not qualify even for herd immunity benefits at the current, and anticipated, low DPT coverage rates. It would be unfortunate indeed if the public sector rollout of the Hib (and DPT)-containing pentavalent vaccine does not reach a herd immunity threshold.

Therefore, to benefit from the Hib vaccine introduction into the public sector, India needs to improve the overall vaccination coverage rates (specifically in the poorer states) and reduce vaccination inequity through an efficient and well-coordinated public sector vaccination service delivery system, and higher public demand for vaccinations. The GOI must ensure timely and high-quality training and communication of vaccination guidelines to health staff, streamlined vaccine supply chain, improved data collection, monitoring and evaluation. ${ }^{12} 44-46$

\section{LIMITATIONS OF THE STUDY}

We assume that all the children who initiated the Hib course in the private sector must have completed the course as scheduled, but that might not be true. However, we note that our calculations are based on the bestoutcome scenarios, in other words, the actual Hib vaccine coverage can be lower than that reported, but not higher.

IMS vaccine data report the number of Hib doses sold in the private sector market, but not necessarily consumed. Furthermore, we assume that IMS Health data on vaccine sales from the hospital and retail pharmacies reflect the true total market utilisation. This assumption seems fair in light of the estimated average $84 \%$ accuracy 
Table 3 Correlation: private sector Haemophilus influenzae type b vaccine coverage and state-specific socioeconomic factors

\section{Correlates}

Per capita state GDP†

Urbanisation (\%) that is, proportion of population living in urban areasł

Schedule caste population $(\%) \ddagger$

Population living below poverty line $(\%) \S$

Female literacy rate $(\%) \ddagger$

Birth in private sector heath facilities (\%)ף

Paediatricians per 1000 childrent†

Proportion of children who received any vaccine in private health facilitiest†

Full vaccination coverage rate (\%)

Private sector vaccine share in coverage against primary childhood diseases (\%) 1 भी

$\mathrm{r}=$ Spearman's rank correlation coefficient.

${ }^{*}$ statistically significant ( $p$ value $<0.05$ ).

†Unidow Analytic Services 2014 . $^{29}$

$\ddagger 2011$ Census of India. ${ }^{24}$

§GOI Planning Commission 2013 . $^{25}$

ףUnicef CES 2009. ${ }^{27}$

††Considers state-wise membership of Indian Academy of Pediatrics as proxy for availability of paediatricians. ${ }^{28}$

¥¥Average of full coverage rates reported by DHS/NFHS 2005-2006 ${ }^{26}$ and Unicef CES 2009. ${ }^{27}$

§.Proportion of children who received one dose of BCG and measles, and three doses of DPT and polio vaccines.

१ीRefers to the percentage of vaccinated children who received a given vaccine (BCG, measles, DPT and oral polio vaccine) in India's private sector market: authors' unpublished calculations.

DPT, diphtheria, pertussis, tetanus; DHS/NFHS, Demographic and Health Survey/National Family Health Survey; GOI, Government of India;

CES, Coverage Evaluation Survey.

(2008-2013: $\mathrm{SD}=2.0 \%)$ of IMS Health data in representing the Indian pharmaceutical market. ${ }^{47}$

\section{CONCLUSION}

The baseline Hib-vaccine coverage prior to public sector rollout, was low among Indian states. The ongoing public sector introduction of the pentavalent vaccine is required if India has to achieve high and equitable Hib vaccine coverage levels. However, all Indian states may not be prepared for pentavalent vaccine introduction in the public sector, notwithstanding the leading states of Kerala and Tamil Nadu.

If public vaccine delivery systems are not upgraded, most of the Indian children living in the states with poorly performing public sectors will not benefit from introduction of the pentavalent vaccine. Further, public sector introduction of the pentavalent vaccine has been made possible through GAVI's financial assistance and the money must be spent judiciously to realise the reported cost-effectiveness ${ }^{48}$ i9 of the nationwide introduction. India needs state-specific microplanning, efficient implementation, disease surveillance and coverage data collection, and timely monitoring and evaluation, to ensure higher vaccination coverage rates.

Future studies are required to identify barriers in successful incorporation of public sector pentavalent vaccine and to check that it does not affect the current DPT coverage levels. As India moves towards upgrading its UIP by introducing newer and more expensive vaccines, public sector vaccination service delivery systems will need to become much more sophisticated. The role of the private sector in contributing to universal Hib vaccination coverage is as yet undefined, but the private sector should not be neglected, as it might be a useful complement to public sector services as they are scaled-up.

\section{Author affiliations}

${ }^{1}$ Department of Global Health, Boston University School of Public Health, Boston, Massachusetts, USA

${ }^{2}$ Center for Global Health and Development, Boston University School of Public Health, Boston, Massachusetts, USA

${ }^{3}$ Indian Institute of Public Health, Public Health Foundation of India, New Delhi, India

Acknowledgements The authors would like to thank Dr. Christopher J Gill (Boston University School of Public Health), Dr. Anthony Janetos and Ms. Cynthia Barakatt (The Frederick S. Pardee Center for the Study of the Longer-Range Future at Boston University) for their useful comments and support.

Contributors AS conceived the idea, designed the analysis, conducted data analysis and wrote the first draft of the paper. AS, WAK and MC conducted the literature review and the interpretation of the results. AS and WAK revised and edited the manuscript to its final stages. MC, HHF and SPZ substantially contributed in acquisition of data for the work and reviewed the manuscript. All the authors approved the final manuscript version.

Funding This study was conducted as AS's summer fellowship project at the Frederick S Pardee Center for the Study of the Longer-Range Future at Boston University, for which he received salary and office support for a period of 10 weeks. The vaccine sales data set was procured from IMS Health through a Bill \& Melinda Gates Foundation grant (22693).

\section{Competing interests None.}

Provenance and peer review Not commissioned; externally peer reviewed.

Data sharing statement The IMS Health data are available on request, at the approval of the IMS Institute for Healthcare Informatics.

Open Access This is an Open Access article distributed in accordance with the Creative Commons Attribution Non Commercial (CC BY-NC 4.0) license, 
which permits others to distribute, remix, adapt, build upon this work noncommercially, and license their derivative works on different terms, provided the original work is properly cited and the use is non-commercial. See: http:// creativecommons.org/licenses/by-nc/4.0/

\section{REFERENCES}

1. Jones G, Steketee RW, Black RE, et al. How many child deaths can we prevent this year? Lancet 2003;362:65-71.

2. Watt JP, Wolfson LJ, O'Brien KL, et al. Burden of disease caused by Haemophillus influenzae type $b$ in children younger than 5 years: global estimates. Lancet 2009;374:903-11.

3. World Health Organization. Estimated Hib and pneumococcal deaths for children under 5years of age, 2000. 2014 (cited 28 Jun 2014). http://www.who.int/immunization/monitoring_surveillance/burden/ estimates/Pneumo_hib_2000/en/index1.html

4. Kahn GD, Thacker D, Nimbalkar S, et al. High cost is the primary barrier reported by physicians who prescribe vaccines not included in India's Universal Immunization Program. J Trop Pediatr 2014;60:287-91.

5. Bairwa M, Pilania M, Rajput M, et al. Pentavalent vaccine: a major breakthrough in India's Universal Immunization Program. Hum Vaccin Immunother 2012;8:1314-16.

6. Mirelman AJ, Ozawaa S, Grewala S. The economic and social benefits of childhood vaccinations in BRICS. Bull World Health Organ 2014;92:454-6.

7. United Nations Children's Fund. The State of the World's Children 2014 In Numbers: Every Child Counts. 2014 (cited 16 Jun 2014) http://www.unicef.org/eapro/EN-FINAL_FULL_REPORT.pdf

8. World Health Organization. India: WHO and UNICEF estimates of immunization coverage: 2013 revision. 2014 (cited 5 Aug 2014). http://www.who.int/immunization/monitoring surveillance/data/ind.pd

9. Expert Group on Hepatitis B and Hib vaccine. Minutes of the expert group meetings on hepatitis B and Hib vaccines. 2010 (cited 17 Jun 2014). http://www.icmr.nic.in/minutes/Minutes\%20Expert\%20Group $\% 20 \% 20 \mathrm{Hepatitis} \% 20 \mathrm{~B} \% 20$ and\%20Hib\%20vaccines.pdf

10. International Vaccine Access Center, Johns Hopkins Bloomberg School of Public Health. Vaccine Information Management System (VIMS) Global Vaccine Introduction Report. 2014 (cited 16 Jun 2014). http://www.jhsph.edu/ivac/vims.html

11. Vashishtha VM, Dogra V, Choudhury P, et al. Haemophilus influenza type $b$ disease and vaccination in India: knowledge attitude and practices of pediatricians. WHO South-East Asia J Public Health 2013;2:101-5.

12. National Technical Advisory Group on Immunization, India. NTAGI Subcommittee Recommendations on Haemophilus influenzae type b (Hib) vaccine introduction in India. Indian Pediatr 2009;46:945-54.

13. Government of India (GOI). GAVI Alliance Annual Progress Report 2012. 2013 (cited 15 Jun 2014). http://www.gavialliance.org/Country/ India/Documents/APRs/Annual-progress-report-India-2012/

14. Adams WG, Deaver KA, Cochi SL, et al. Decline of childhood Haemophilus influenzae type $b$ (Hib) disease in the Hib vaccine era. JAMA 1993;269:221-6.

15. Adegbola RA, Secka O, Lahai G, et al. Elimination of Haemophilus influenzae type $\mathrm{b}(\mathrm{Hib})$ disease from The Gambia after the introduction of routine immunisation with a Hib conjugate vaccine: a prospective study. Lancet 2005;366:144-50.

16. Cowgill KD, Ndiritu M, Nyiro J, et al. Effectiveness of Haemophilus influenzae type $b$ conjugate vaccine introduction into routine childhood immunization in Kenya. JAMA 2006;296:671-8.

17. Lewis RF, Kisakye A, Gessner BD, et al. Action for child survival: elimination of Haemophilus influenzae type $b$ meningitis in Uganda. Bull World Health Organ 2008;86:292-301.

18. Verghese VP, Friberg IK, Cherian T, et al. Community effect of Haemophilus influenzae type B vaccination in India. Pediatr Infect Dis J 2009;28:738-55.

19. GOI Ministry of Health \& Family Welfare and WHO India. Operational Guidelines: Introduction of Haemophilus influenzae b (Hib) as Pentavalent Vaccine in Universal Immunization Program of India. 2013 (cited 16 Jun 2014). http://www.searo.who.int/india/ topics/routine_immunization/Operational_Guidelines_for introduction_Hib_as_Pentavalent_vaccine_2013.pdf

20. IMS Health. http://www.imshealth.com

21. Kaplan WA, Wirtz VJ, Stephens P. The market dynamics of generic medicines in the private sector of 19 low and middle income countries between 2001 and 2011: a descriptive time series analysis. PLOS ONE 2013;8:e74399.

22. Garabedian LF, Ross-Degnan D, Ratanawijitrasin S, et al. Impact of universal health insurance coverage in Thailand on sales and market share of medicines for non-communicable diseases: an interrupted time series study. BMJ Open 2012;2:e001686.

23. Leopold C, Mantel-Teeuwisse AK, Vogler S, et al. Effects of the economic recession on pharmaceutical policy and medicine sales in eight European countries. Bull World Health Organ 2014;92:630-40.

24. GOI Ministry of Home Affairs. Census of India. 2011 (cited on 15 May 2014). http://censusindia.gov.in/

25. GOI Planning Commission. Data-book for use of Deputy Chairman, Planning Commission. 2014 (cited 15 May 2014). http:// planningcommission.nic.in/data/datatable/1203/databook_1203.pdf

26. International Institute for Population Sciences and Macro International Inc. NATIONAL FAMILY HEALTH SURVEY (NFHS-3): India. 2007 (cited 10 April 2014). http://dhsprogram.com/ publications/publication-FRIND3-DHS-Final-Reports.cfm

27. United Nations Children's Fund. Complete Evaluation Survey 2009: All India Report. 2010 (cited 7 April 2014). http://www.unfpa.org/ sowmy/resources/docs/library/R309_UNICEF_2010_INDIA_ 2009CoverageSurvey.pdf

28. Indian Academy of Pediatrics. An Organizational Overview. State-wise details of membership of IAP as on 8th October 2012 2012 (cited 9 May 2014). http://www.iapindia.org/files/ ORGANIZATIONAL_OVERVIEW_2_NOVEMBER_2012.pdf

29. Unidow Analytic Services. GDP of Indian States and Union Territories 2012. 2014 (cited 15 May 2014). http://unidow.com/india $\% 20$ home\%20eng/statewise_gdp.html

30. Gupta SK, Sosler S, Lahariya C. Introduction of Haemophilus influenzae type b (Hib) as pentavalent (DPT-HepB-Hib) vaccine in two states of India. Indian Pediatr 2012;49:707-9.

31. Indian Academy of Pediatrics Committee on Immunization. IAP guide book on immunization 2009-2011. Mumbai: Indian Academy of Pediatrics, 2011 (cited 3 Jun 2014). http://www.iapindia.org/files/ IAP\%20Immunization\%20Guide\%20Book_2009_2010.pdf

32. Kaur H, Sharma S, Agarwal A. Hib vaccine in India: a case for universal immunization. Vaccine 2013;31:3763-5.

33. R Core Team. R: A Language and Environment for Statistical Computing. Austria: Foundation for Statistical Computing, 2014 (cited 15 May 2014). http://www.r-project.org/

34. Mathew JL. Inequity in childhood immunization in India: a systematic review. Indian Pediatr 2012;49:203-23.

35. Singh PK. Trends in child immunization across geographical regions in India: focus on urban-rural and gender differentials. PLOS ONE 2013;8:e73102.

36. Vikram K, Vanneman R, Desai S. Linkages between maternal education and childhood immunization in India. Soc Sci Med 2012;75:331-9.

37. Dytham C. Choosing and using statistics: a biologist's guide, 3rd edn. Sussex, UK: Wiley-Blackwell, 2011.

38. Deogaonkar M. Socio-economic inequality and its effect on healthcare delivery in India: Inequality and healthcare. Electronic J Sociol 2004 (cited 19 May 2014). http://www.sociology.org/content/ vol8.1/deogaonkar.html

39. Malhotra C, Do YK. Socio-economic disparity in health system responsiveness in India. Health Policy Plan 2013;28:197-205.

40. Kim S. Package 'ppcor': partial and semi-partial (Part) correlation. 2012 (cited 4 Oct 2014). http://cran.r-project.org/web/packages/ ppcor/ppcor.pdf

41. Howard DH, Roy K. Private care and public health: do vaccination and prenatal care rates differ between users of private versus public sector care in India? Health Serv Res 2004;39:2013-26.

42. Singh P, Yadav RJ. Immunization status of children in BIMARU states. Indian J Pediatr 2001;68:495-9.

43. Kusuma YS, Kumari R, Pandav CS, et al. Migration and immunization: determinants of childhood immunization uptake among socioeconomically disadvantaged migrants in Delhi, India. Trop Med Int Health 2010;15:1326-32.

44. Kaufmann JR, Roger Miller R, Cheyne J. Vaccine supply chains need to be better funded and strengthened, or lives will be at risk. Health Affairs 2011;30:1113-21.

45. Madhavi Y, Jacob M, Puliyel JM, et al. Evidence-based National Vaccine Policy. Indian J Med Res 2010;131:617-28.

46. Pradhan SK. Time to revamp the universal immunization program in India. Indian J Public Health 2010;54:71-4.

47. IMS Health. Acts 2013: IMS Health Quality Assurance. 2013 (cited 17 Aug 2014). http://us.imshealth.com/actsonline/acts2013.pdf

48. Clark AD, Griffiths UK, Abbas SS, et al. Impact and cost-effectiveness of Haemophilus influenzae type b conjugate vaccination in India. J Pediatr 2013;163:S60-72.

49. Gupta M, Prinja S, Kumar R, et al. Cost-effectiveness of Haemophilus influenzae type b $(\mathrm{Hib})$ vaccine introduction in the universal immunization schedule in Haryana State, India. Health Policy Plan 2013;28:51-61. 